\title{
A Review on the School - Based Learning Activity Sheet Towards Improvement of Instructional Material
}

\author{
Faye Joy F. Delos Reyes*, Dennis G. Caballes** \\ * Commonwealth High School, Department of Education \\ ${ }^{* *}$ De La Salle - College of Saint Benilde \\ DOI: 10.29322/IJSRP.11.08.2021.p11627 \\ http://dx.doi.org/10.29322/IJSRP.11.08.2021.p11627
}

\begin{abstract}
Education is essential for each person's personal interests as well as his role as a citizen. The utilization of instructional material is linked to the advancement of knowledge and technology while being consistent with national and educational objectives. Educators convey the subject and learners acquire it in daily tasks that become routines. Learners, of course, require engaging instructional materials as a tool for gathering information during the learning process, therefore learning materials with exciting innovations are required so that students are motivated to learn. The aim of the study was to assess the views and opinions of the learners on the utilization of Learning Activity Sheets (LAS), gain improvements from colleagues and other Science teachers and lastly, to evaluate the existing LAS. The result shows that upon learners perceived the LAS as neutral wherein it can be an effective instructional material. It can imply that the instructional material should be creative and appealing to increase learner's interest. Moreover, additional pictures on the LAS were one of the improvements stated by the teachers. The study can recommend that when creating learning activities, it's important to consider how students process new information, learn new skills, or establish a new way of thinking. Learning activities must also be created in such a way that they lead to the fulfillment of the course and program objectives. The process of activity design is the methodical planning of learning experiences to achieve those two objectives. Adherence to an explicit design process is the first step in creating effective, high-quality learning activities. Learning outcomes must be examined both during and after each activity to ensure that the activity delivered the necessary depth of comprehension. The activity should also be evaluated to see how it may be improved for future use.
\end{abstract}

Index Terms- instructional material, learning activity sheet, student - centered approach, alternative delivery modes

\section{INTRODUCTION}

$\mathrm{E}^{\mathrm{s}}$ ffective education is the foundation for gainful work, personal growth, economic stability, moral reasoning, and constructive interpersonal interactions in today's world; its absence means ignorance, underdevelopment, maladjustment, crime, poverty, and frustration, among other things. Education acts as a road map for developing people who will be able to confront and innovate issues that will be important in the future.

As we faced the pandemic, the school, teachers and learners adopt to the changes. Everyone was forced to adapt to all of the changes that were necessary. The Department of Education (DepEd) provided one solution in DepEd Order No. 12 series 2020 [1], which facilitates the adoption of Most Essential Learning Competencies (MELCs) and prohibits face-to-face classes. The distribution of the MELCs is core of the Department's long-term reaction, particularly during emergencies, as well as a response to the current pandemic's issues; thus, it can be utilized as a tool to assure curricular consistency in specific circumstances. Because we anticipate challenges in learning delivery, the MELCs will allow us to focus instruction on the most essential skills for our students to gain. It will also make the transition to distance learning tools based on classroom-based learning technologies easier. It is suggested that in the current scenario, several modalities and materials be used. Because face-to-face classrooms are still restricted owing to public health concerns, combining Self Learning Modules (SLMs) with alternate learning delivery modalities (modular, television-based, radio-based teaching, mixed, and online) will ensure that all students have access to a high-quality basic education.

Teachers should be able to have the abilities necessary to make teaching effective in this new normal. Using the appropriate instructional material on the topic is one of the abilities that a teacher should possess. Every subject in the educational system requires the use of instructional resources. It allows students to communicate with words, concepts, and notions in ways that improve their reading, listening, problem-solving, viewing, thinking, speaking, and writing skills, as well as their ability to use media and technology. Instructional materials stand out because they are physical objects that students may utilize. A learner engages with the content throughout such use. A learner manipulating educational material and expressing his or her views on the problem and idea embodied in the content is one example of such interaction. The teacher is then informed by any feedback acquired from such use as to the amount to which a learner has achieved an educational goal [2]. The purpose of instructional materials is to offer teachers with feedback on how 
students viewed each topic and achieved mastery over it. It will also serve as a tool for determining each learner's degree of comprehension.

Several studies have shown that instructional materials increase the teaching and learning process while also allowing teachers and students to engage as human beings in a setting where people control their surroundings for their own best interests. It also demonstrated that, when employed effectively in teaching learning contexts, instructional materials can achieve a wide range of complicated tasks. It also provides real-life experiences for teachers, providing them with a foundation for thinking and comprehending. It also provides a realistic foundation for conceptual thinking, reducing the number of nonsensical responses from students [3]. The teacher can use instructional resources to assess the learner's challenges. It makes it possible for students to understand concepts more quickly and efficiently. It also aids in the clarification of information by simplifying, highlighting, and emphasizing them.

In terms of academic attainment, worksheets can be helpful in a number of ways. Worksheets, for example, can be used to enhance textbooks by adding information specific to specific classes. Furthermore, voids in worksheets offer opportunities for pupils to fill in gaps and build knowledge. When used in conjunction with appropriate teaching approaches, well-designed worksheet questions can pique students' interest. Worksheets also serve a variety of purposes in various circumstances [4]. Worksheets can be used by teachers as an assessment tool to comprehend students' prior knowledge, learning outcomes, and learning processes, and they can also be used by students to track their own learning progress. The Learner Activity Sheet (LAS) is one type of material that can be employed (worksheet). Teachers and students will benefit from the worksheet. Media is a message-channeling tool that can excite students' thoughts, feelings, and talents in order to make the teaching and learning process more effective and efficient [5]. The teacher can assess the learner's knowledge by using this material. Not only it would be used as an assessment but also as a source of communication between the teacher and the learner. The goal of LAS is to give students the opportunity to take an active role in their learning by assisting them in developing and discovering concepts through science process skills, as well as to serve as a resource for teachers and learners during the learning process. It can also be used as a step-by-step guide for experiments, demonstrations, and conversations [6]. In this, the learners can decide which are the concepts vital on the topic and relate it with the natural environment.

\section{RESEARCH ELABORATIONS}

In the delivery of instructions, instructional materials serve as a conduit between the teacher and the students. They may also be used to motivate students during the teaching-learning process. It is used to keep students' attention and alleviate boredom [7]. Lesson plans are frequently based on instructional materials. Teachers will also require these tools in order to assess their pupils' knowledge. Teachers frequently evaluate pupils by assigning assignments, developing projects, and administering tests. For all of these activities, instructional materials are required. The alignment of the activity sheets with the curriculum was one of the principles that the teacher should always keep in mind when developing instructional material. It was critical that the target competencies be met in order to improve the learning process.

However, a fundamental goal shared by all teachers is to keep lesson presentations current, exciting, and challenging for their learners. This will assist the teacher in personalizing the learning technique as well as the content, as well as working in accordance with the needs of the learners. The most effective way to achieve this goal is to employ instructional materials [8]. As the instructional materials can be modified, created by the teachers, this can be able to increase learners' motivation to learn. In this way, it can assure that the teaching - learning process will be effective. Teachers must be able to create a variety of instructional resources so that learners' knowledge does not become routine or dull. The goal of science education is for learners to make not only information, understanding, a positive attitude, and skill, but also a desire to learn about natural surroundings. The capacity of teachers to educate determines the success of individuals in their learning. As a result, in order to meet these requirements, educators must be creative in developing new teaching resources. Science learning is integrated in activities that begin with the use of a variety of learning tools to describe a phenomenon [9].

It is critical for the teacher to choose acceptable information for each topic that is relevant to the learner's experiences and perceptions while crafting instructional material. Situations are made up of all the items, people, and symbols in a learner's environment. A person's response to a circumstance in the past will help them respond to a similar scenario in the future. A situation must be established in which the learner is satisfied. Under this area, we cover all of the person's abilities as well as all of the customary answers that they bring to the scenario. Individual attention can be piqued through the use of instructional material. The learner's objective is something he wants to achieve. Because goals lead efforts, the teacher's motivation challenge is fundamentally one of setting up a situation with instructional content in which the student can perceive the goals he wants to achieve. Interpretation: When a person interprets a circumstance, he or she is deciding what to do next. It will be simple for a teacher and a student to forecast what will unfold if various efforts are conducted provided appropriate aids are made accessible. Action: A person selects the intervention that he believes will provide him with the most pleasure. The term "consequence" refers to the actions that precede their outcomes. If instructional materials are used, the prognosis will be fulfilling, and the repercussions will validate the person's efforts, making him feel completely satisfied [10]. The learner will be able to manage the traits in the education process by demonstrating this behavior.

This publication is licensed under Creative Commons Attribution CC BY.

http://dx.doi.org/10.29322/IJSRP.11.08.2021.p11627

WWW.ijsrp.org 
The policy under DepEd Order No. 18 series of 2020 [11], aims to establish the guidelines that will enable the Department of Education (DepEd) to provide learning resources and implement the Basic Education - Learning Continuity Plan (BE - LCP) to ensure that learning opportunities should be provided to the learners in a safe manner, using various learning delivery methods. LAS were included in SLMs and are used to assess the learners' level of knowledge throughout the course.

The LAS is a measure of learners' activity in understanding to integrate or perform what they've learned. The sheet is crucial in encouraging children to absorb and internalize the information presented. The teacher can monitor learners who have grasped the content and those who have not yet grasped it while concentrating on the activity sheet. This sheet is one of the teaching materials used to enhance the teacher's function and is critical to the learning process' efficacy. With LAS that are based on scientific principles, the teacher's role is reduced to that of a facilitator rather than the primary source of learning. Students are expected to identify difficulties, consider alternate solutions, and assess the settlement results while working on activity sheets. Because it was made general, the learners were only taught about the subject that had previously been taught by the teacher, and no problem-solving abilities were taught. The student activity sheets are important in the learning process because they feature learning activities in which all students can participate visually, audibly, or physically.

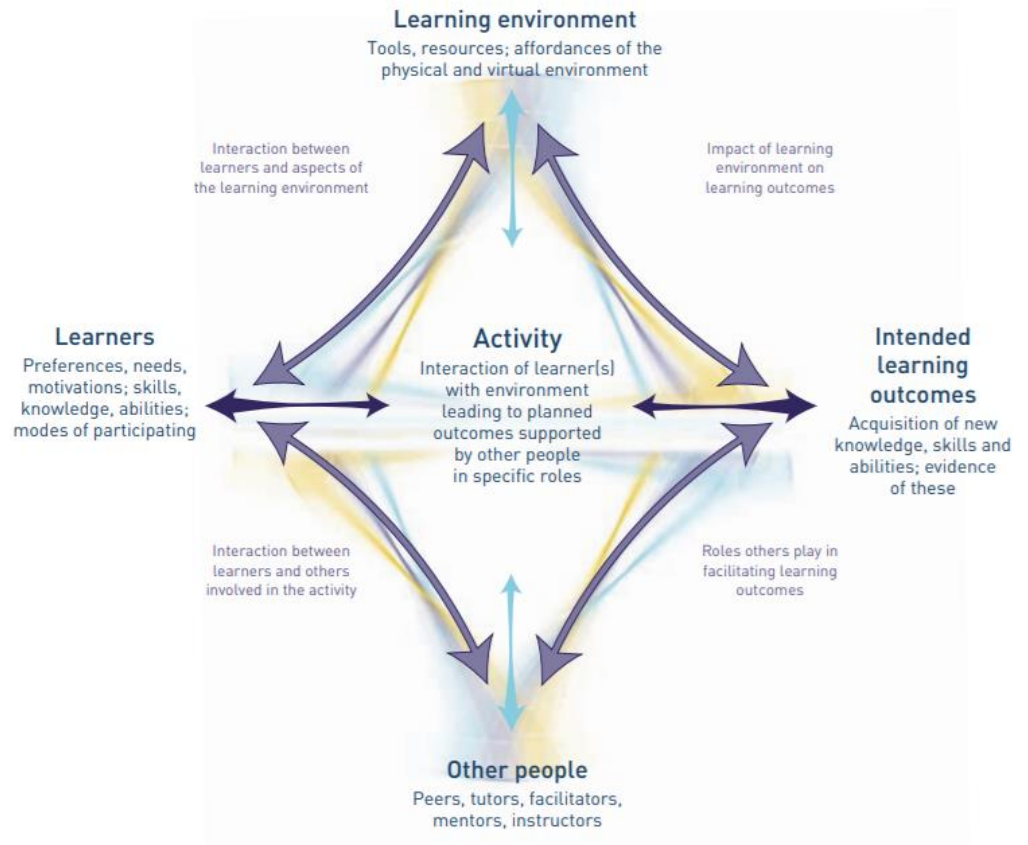

Figure 1: Learning Activity Model

A learning activity model is a specialized interaction of learners with others that involves the use of certain skills and information and is aimed at specified goals. When planning an activity to engage learners and improve their growth, a practitioner must consider a number of factors. These challenges are better illustrated by a model of learning activity design. The elements of design are intertwined in reality, but the model can be used as a verification to guarantee that all four aspects have been evaluated and taken into sync with one another and with the underlying learning strategy [12]. The model would stress the elements' interconnectedness. It would be appropriate if each learner's learning activities could cover the entire topic. The interaction of these components will be flexible and asymmetrical within the context of every activity. The principles that drive design in any given environment will be impacted by the practitioner's assessments of the learners' needs and the expected results, and will involve a number of intervening tools and resources as well as a variety of public discourses.

In the current circumstances, learners choose modular distance learning as part of the DepEd's continuity plan. The researcher devised three specific research objectives as part of the study: 1. To determine the views and opinions of the learners in the utilization of LAS; 2. To gain improvements from colleagues and other Science teachers; and, 3. To evaluate the current LAS used.

A mixed method research was used in this study. It polled teachers and students about how to enhance the current LAS. The study's respondents were 30 Science teachers and 30 Grade 9 students who voluntarily participated in the study. The respondents were from one of Quezon City's chosen secondary school during the academic year 2020-2021. The research tool to be used in the study was composed of two parts. The first part of the questionnaire was the rubrics. The approach analyzes this rubric from a journal article 
entitled "The Role of Rubrics in Learning and Implementation of Authentic Assessment: A Literature Review" and asks the authors for consent to use one of the rated rubrics. Permission was granted when an email was sent to them noting that the rubrics will be unmodified when it will be used in the study. The study's rubric was an analytic rubric, which consisted of a three-point grading scale separated into five components. It was decided to utilized by the researcher because it could cover all of the main points in the LAS and can pin point the missing gaps. An analytic rubric is without a doubt one of the most intriguing terms to contemplate. The analytic rubric, in theory, gives full descriptions of each and every criterion at all levels. Even before the classes begin, students who have the rubric in hand have a clearer vision of what they need to accomplish and are actively mapping out their own paths to attain the goals. Quarter 1, Week 5 was chosen as the LAS to be examined in the study which directly addresses species extinction and its causes. Moreover, to determine the feedback for both the learner and teacher, a narrative question was provided at the last part of the questionnaire for the comments and suggestions of the respondents.

The qualitative data that were collected was analyzed using the SPSS ver. 23 statistical software. Specific remarks, ideas, and additional improvements for the teacher together with the views and opinions of the learners on the utilization of LAS were determined using descriptive analysis. A statistical mean and standard deviation were employed to check the existing LAS using the rubrics. In addition, an interrater with a colleague was completed to ensure that the data collected was accurate.

\section{RESULTS AND FINDINGS}

\section{A. The Respondents Views and Opinions on the Utilizations of LAS}

The existing Learning Activity Sheet was used among the Grade 9 level learners was about Species Extinction. To determine the views and opinions on the utilization of LAS, the result shows the computed mean of 2.3 (neutral) for learners. Through the designed worksheets, students were able to appreciate the material in a pleasant way. Worksheets have proven to be an effective tool for teaching. Worksheets can help learners stay motivated and retain information by facilitating positive involvement and demonstrating a cognitive capacity [13]. The use of a variety of instructional tools to boost the learners' interest and add competence to the subject matter is an element of the teaching - learning process. Learners are also urged to apply their critical thinking abilities to make it easier to learn their subjects. Instructional materials will assist students in carrying out their learning activities effectively if these activities are of interest to them, resulting in strong academic performance. It is preferable to have instructional materials that can drive students to improve their abilities while also improving their academic achievement. Because all learners are required to engage in the class and use worksheets to learn scientific processes, Teachers must use worksheets produced in accordance with current learning theories, and research into the challenges found during this process must be conducted using a variety of ways [14].

The scientific approach is a student-centered learning process that allows students to actively develop concepts, laws, or principles by watching, inquiring, trying, digesting information, and sharing what they've learned. The scientific approach is meant to assist learners in knowing and comprehending numerous subjects using a scientific approach, recognizing that information can come from anywhere, at any time, and is not limited to the teacher's in-line information. The learning environment should promote active learners to learn from a variety of sources through conversation, observation, and practice [16]. As the learners criticize the worksheet, some of their opinions were determined. The worksheet that was used by the learners states the relationship of environmental problems on the extinction of species. It also provides the major cause of species extinction which was pollution and its types including the human factors on destroying biodiversity. As the learners can be able to expound on these, they have critically thought on some ways that could somehow save the environment, innovate materials which could be vital on eliminating pollution or being advocated on preserving the environment and the species. The worksheet also required the learners to create a slogan which will be used as a campaign on saving the environment. A collaborative approach was used within the learners to assess their knowledge and skills working with groups.

\section{B. Improvements from Colleagues and other Science Teachers}

The result shows that the computed mean of 2.57 (strongly agree) for the teachers can infer that the LAS used can be used as an instructional material preferably as a worksheet. These learners' direct involvement can help them develop all elements of their personalities, including attitudes, knowledge, and abilities. Students have a hard time generating and executing concepts on their own, thus learning that engages them directly has a lot of obstacles. This occurs as a result of the lack of diversity in the learning models and methodologies used by teachers. During the learning process, learners are motivated to obtain knowledge through the usage of student worksheets. As a result, phases in the scientific process for students should be included in the student worksheet. In this instance, the teacher as a mentor must be able to connect students' experiences with difficulties of daily life that are related to learning. If students recognize that the connection between what they've studied and the real world is a significant issue for them, they'll be more motivated to learn [15]. In developing an instructional material like worksheets, it was best that it could be related on the real - life like situations of the learners or near from it because with this, the learners can be able to analyze the facts and gain mastery from the topic. The teachers also mentioned that they conducted a detailed review of the pandemic's potential impact on biodiversity preservation, considering that many limitations have been enacted and pollution has decreased. Using this detailed review, the learners can be able to identify the possible solutions that can be implemented to preserve the environment and prevent extinction of species.

This publication is licensed under Creative Commons Attribution CC BY.

http://dx.doi.org/10.29322/IJSRP.11.08.2021.p11627

WWW.ijsrp.org 
However, one of the worksheet's notable improvements was the addition of additional graphics to help learners understand circumstances that might have occurred during ancient times. It will be critical to their learning if they can distinguish each period from the next, as well as recognize significant creatures. Because the student activity sheets are presented with engaging pictures or images, the experience of using them in conjunction with a scientific approach in the learning process should be able to promote student curiosity. Because each command has attractive visuals and graphics, students will not quickly become bored while working on questions or activities.

\section{REFERENCES}

[1] DepEd Order No. 12 Series 2020 "Adoption of the Basic Education Learning Continuity Plan for School Year 2020 - 2021 in light of the Covid - 19 Public Health Emergency". Department of Education. https://www.deped.gov.ph/wpcontent/uploads/2020/06/DO_s2020_012.pdf

[2] S. Amadioha, "The Importance of Instructional Materilas in our Schools: An Overview"

[3] S.K. Olawale, "The Use of Instructional Materials for Effective Learning of Islamic Studies". 2013. Jihat-al-Islam, 6, 29-40

[4] C. Lee, "Worksheet Usage, Reading Achievement, Classes' Lack of Readiness and Science Achievement: A Cross - Country Comparison". 2014. International Journal of Education in Mathematics, Science and Techology, Volume 2, Number 2, April 2014, Page 96 - 106. ISSN:2147 - 611X

[5] M. Siahaan, M. Sirait, "Development of Student Activity Sheet (Worksheet) Based on Guided Inquiry to Improve Student's Critical Thinking Skills in Senior High School". 2017. Journal of Education and Practice, Volume 8, Number 20. ISSN: 2222 - 288X

[6] A. Fauziah, T. Nurita, "Activities of Students in Using Worksheet Based on Contextual Teaching and Learning". 2019. IOP Publishing, Journmal of Phyics: Conference Series. 1417 (2019) 012088

[7] S. Adalikwu, I. Iorkpilgh, "The Influence of Instructional Materials on Academic Performance of Senior Secondary School Students in Chemistry in Cross River State", 2013. Global Journal of Educational Reseacrh, Volume 12, 2013: 39 - 45. ISSN: 1596 - 6224

[8] O. Effiong, C. Igiri, "Impact of Instructional Materials in Teaching and Learning of Biology in Senior Secondary Schools in Yakurr LG A.”, 2015. International Letters of Social and Humanistic Sciences, Volume 62, pp. 27 - 33. ISSN: 2300 - 2697

[9] A. Amila, A. Abdurrahman, D. Wayan, H. Kartini, Practicality and Effectiveness of Student Worksheets Based on Ethno Science to Improve Conceptual Understanding in Rigid Body", 2018. International Journal of Advanced Engineering, Management and Science, Volume 4, Issue 5. ISSN: 2454 - 1311

[10] M. Dahar, F. Faize, "Effect of the Availability and Use of Instructuional Materials on Academic Performance of Students in Punjab (Pakistan)", 2011. Middle Eastern Finance and Economics, Issue 11. ISSN: 1450 - 2889

[11] DepEd Order No. 18 Series 2020 "Policy Guidelines on the Provision of Learning Resources in the Implementation of the Basic Education Learning Continuity Plan". Department of Education. https://www.deped.gov.ph/wp-content/uploads/2020/08/DO_s2020_018.pdf

[12] S. Knight, "Effectiuve Practice in Digital Age", 2009

[13] V. Monding, J. Buniel, "Effectiveness of Developed Worksheets to the Academic Achievement of Students in Science 9 Concepts", 2021. International Journal for Innovation Education and Research. ISSN: $2411-2933$

[14] U. Toman, A. Akdeniz, S. Cimer, F. Gurbuz “ Extended Worksheet Developed According to5E Model Based on Constructivist Learning Approach", 2013. International Journal on New Trends in Education and Their Implication, Volume 4, Article 16. ISSN: 1309 - 6249

[15] M. Ningrum, Yulkifli, R. Abdullah, Y. Nasution, "Preliminary Study in the Student Worksheet Development Using Inquiry Based Learning Model in Science Process Skills Approach for Physics Learning of Second Grade High School. IOP Publishing, Jounal of Physics. 1317 (2019) 012163

\section{AUTHORS}

First Author - Faye Joy F. Delos Reyes, Teacher 1, Commonwealth High School, delosreyes1902690@ceu.edu.ph Second Author - Dennis G. Caballes, Professor, De La Salle - College of Saint Benilde, dennis.caballes@ benilde.edu.ph

Correspondence Author - Faye Joy F. Delos Reyes, Teacher 1, Commonwealth High School, fayedr29@gmail.com, $+639472683431$ 